\title{
Should dual antiplatelet therapy be used in patients following coronary artery bypass surgery? A meta-analysis of randomized controlled trials
}

Subodh Verma ${ }^{1,5,8,11^{*}}$, Shaun G. Goodman ${ }^{2,6,9}$, Shamir R. Mehta ${ }^{12,13}$, David A. Latter ${ }^{1,5,8}$, Marc Ruel ${ }^{14}$, Milan Gupta ${ }^{9,12,15}$, Bobby Yanagawa ${ }^{1,5,8}$, Mohammed Al-Omran ${ }^{3,5,8,11}$, Nandini Gupta ${ }^{16}$, Hwee Teoh ${ }^{1,4,5,6}$ and Jan O. Friedrich ${ }^{6,7,9,10^{*}}$

\begin{abstract}
Background: We assessed the effectiveness of dual antiplatelet therapy (DAPT) post elective or urgent (i.e., post acute coronary syndrome $[A C S]$ ) coronary artery bypass graft surgery (CABG).

Methods: We systematically searched MEDLINE, EMBASE, and the Cochrane Registry from inception to August 2015. Randomized controlled trials (RCTs) in adults undergoing CABG comparing either dual vs. single antiplatelet therapy or higher- vs. lower-intensity DAPT were identified.

Results: Nine RCTs ( $n=4,887)$ with up to $1 y$ follow-up were included. Five RCTs enrolled patients post-elective CABG $(n=986)$. Two multi-centre RCTs enrolled ACS patients who subsequently underwent CABG $(n=2,155)$. These 7 RCTs compared clopidogrel plus aspirin to aspirin alone. Two other multi-centre RCTs reported on ACS patients who subsequently underwent CABG comparing higher intensity DAPT with either ticagrelor $(n=1,261)$ or prasugrel $(n=485)$ plus aspirin to clopidogrel plus aspirin. Post-operative anti-platelet therapy was started when chest tube bleeding was no longer significant, typically within 24-48 h. There were no differences in all-cause mortality in clopidogrel plus aspirin vs. aspirin RCTs; conversely, all-cause mortality was significantly lower in ticagrelor and prasugrel vs. clopidogrel RCTs (risk ratio[RR] 0.49, $95 \%$ confidence interval[Cl] 0.33-0.71, $p=0.0002 ; 2$ RCTs, $n=1695$; $P^{2}=0 \%$; interaction $p<0.01$ compared to clopidogrel plus aspirin vs aspirin RCTs). There were no differences in myocardial infarctions, strokes, or composite outcomes. Overall, major bleeding was not significantly increased (RR 1.31, $95 \% \mathrm{Cl} 0.81-2.10, p=0.27 ; 7 \mathrm{RCTs}, n=4500)$. There was heterogeneity $\left(P^{2}=42 \%\right)$ due almost entirely to higher bleeding reported for the prasugrel RCT which included mainly CABG-related major bleeding (RR 3.15, $95 \%$ Cl 1.45-6.87, $p=0.004 ; 1$ RCT, $n=437)$.

(Continued on next page)
\end{abstract}

\footnotetext{
* Correspondence: vermasu@smh.ca; FriedrichJ@smh.ca

${ }^{1}$ Division of Cardiac Surgery, Keenan Research Centre for Biomedical Science

and Li Ka Shing Knowledge Institute of St. Michael's Hospital, Toronto, ON M5B 1W8, Canada

${ }^{6}$ Department of Medicine, St. Michael's Hospital, Toronto, ON M5B 1W8,

Canada

Full list of author information is available at the end of the article
} 
(Continued from previous page)

Conclusions: Most RCT data for DAPT post CABG is derived from subgroups of ACS patients in DAPT RCTs requiring $C A B G$ who resume DAPT post-operatively. Limited RCT data with heterogeneous trial designs suggest that higher intensity (prasugrel or ticagrelor) but not lower intensity (clopidogrel) DAPT is associated with an approximate $50 \%$ lower mortality in ACS patients who underwent CABG based on post-randomization subsets from single RCTs. Large prospective RCTs evaluating the use of DAPT post-CABG are warranted to provide more definitive guidance for clinicians.

Keywords: Coronary artery bypass graft surgery, Acute coronary syndrome, Anti-platelet therapy, $\mathrm{P} 2 \mathrm{Y}_{12}$ antagonists, Systematic review, Meta-analysis

\section{Background}

Dual antiplatelet therapy (DAPT) with acetylsalicylic acid (ASA) and an oral $\mathrm{P}_{2} \mathrm{Y}_{12}$ antagonist, is the cornerstone for management of patients presenting with acute coronary syndrome (ACS). Although there are no recommendations regarding DAPT treatment post elective CABG, guidelines recommend that therapy with DAPT be continued for one year following ACS (non-ST segment elevation myocardial infarction [NSTEMI], ST-elevation myocardial infarction [STEMI] or unstable angina), irrespective of whether patients are managed medically or invasively with either percutaneous coronary intervention or coronary artery bypass graft (CABG) surgery $[1,2]$. The evidence supporting the benefit of DAPT in ACS patients has been based largely on three landmark trials, namely CURE [3], TRITON-TIMI 38 [4] and PLATO [5]. Whereas cardiac surgeons are well versed with the guidelines regarding discontinuation of DAPT prior to CABG to minimize bleeding risks $[6,7]$, there is considerable variability in DAPT resumption in ACS patients post CABG [8-10]. Since only a small proportion of patients in large trials undergo CABG, individual RCTs have not been adequately powered to address the role of DAPT in the post-CABG cohort. We therefore, conducted a meta-analysis of RCTs to evaluate the benefits of DAPT resumption in post CABG patients, either elective or post ACS, using all-cause mortality as the pre-specified primary endpoint.

\section{Methods}

\section{Data sources}

We systematically searched OVID versions of MEDLINE (1946 through to August 2015, week 2), EMBASE Classic and EMBASE (1947 through 2015 week 34), and the Cochrane Central Register of Controlled Trials (July 2015) for relevant studies using search terms for anti-platelet agents and coronary artery bypass surgery, and published sensitive filters to identify randomized controlled trials (RCTs) (Fig. 1). We also searched bibliographies of included studies and personal files. We did not impose language restrictions.

\section{Study Selection}

We included prospective clinical trials randomizing adult patients with coronary artery disease undergoing CABG either 1) to dual vs single antiplatelet therapy (e.g., clopidogrel plus ASA vs ASA alone) or 2) to higher vs lower intensity dual antiplatelet therapy (e.g., ticagrelor or prasugrel plus ASA vs clopidogrel plus ASA). To meet inclusion criteria, RCTs had to either include only patients undergoing CABG, or report outcomes separately in subgroups of patients with ACS who underwent CABG. Studies were excluded if patients were not randomized between treatment groups or if outcomes were not reported separately for patients undergoing CABG. Citations were screened in duplicate and full text review was conducted to determine eligibility when either screening reviewer felt a citation potentially met inclusion criteria.

\section{Data Extraction and Quality Assessment}

Details of the publication (i.e., trial authors and acronym, enrolment period, year of publication), inclusion/ exclusion criteria, demographics and cardiac risk factors of the enrolled patients, description of the interventions used, and outcome definitions and events were collected and collated. Risk of bias in RCTs (including blinding of participants, method of sequence generation and allocation concealment, intention-to-treat analysis, early trial stopping for efficacy before the planned enrollment was completed, and loss to follow-up) was also assessed.

\section{Data Analysis}

Our primary hypothesis was that all-cause mortality at the longest duration of follow up is decreased in patients undergoing $C A B G$ randomized to dual antiplatelet therapy vs patients randomized to lower intensity dual or single antiplatelet therapy. Secondary outcomes, also at the longest duration of follow up, included non-fatal myocardial infarction (MI); non-fatal stroke; the composite outcome of cardiovascular (alternatively all-cause) mortality or non-fatal MI or non-fatal stroke; and bleeding (major bleeding, preferably non-CABG related, if 
MEDLINE <1946 to August Week 2 2015> and EMBASE Classic+EMBASE <1947 to 2015 Week 34>

1 (clopidogrel or ticagrelor or prasugrel).mp. $(53,624)$

2 (coronary artery bypass or cardiac surgery or heart surgery or CABG).mp. $(259,397)$

31 and $2(5,117)$

4 random:.tw. or clinical trial:.mp. $(3,145,438)$ [EMBASE sensitive filter for randomized trials]

5 clinical trial.mp. or clinical trial.pt. or random:.mp. or tu.xs. $(6,193,652)$ [MEDLINE sensitive filter for randomized trials]

63 and (4 or 5) $(2,414)$

7 remove duplicates from $6(\underline{\mathbf{2}, 148})$

Cochrane Central Register of Controlled Trials: Issue 7 of 12 July 2015

1 clopidogrel coronary bypass (222) [citations containing all three terms anywhere in title, abstract, or keywords]

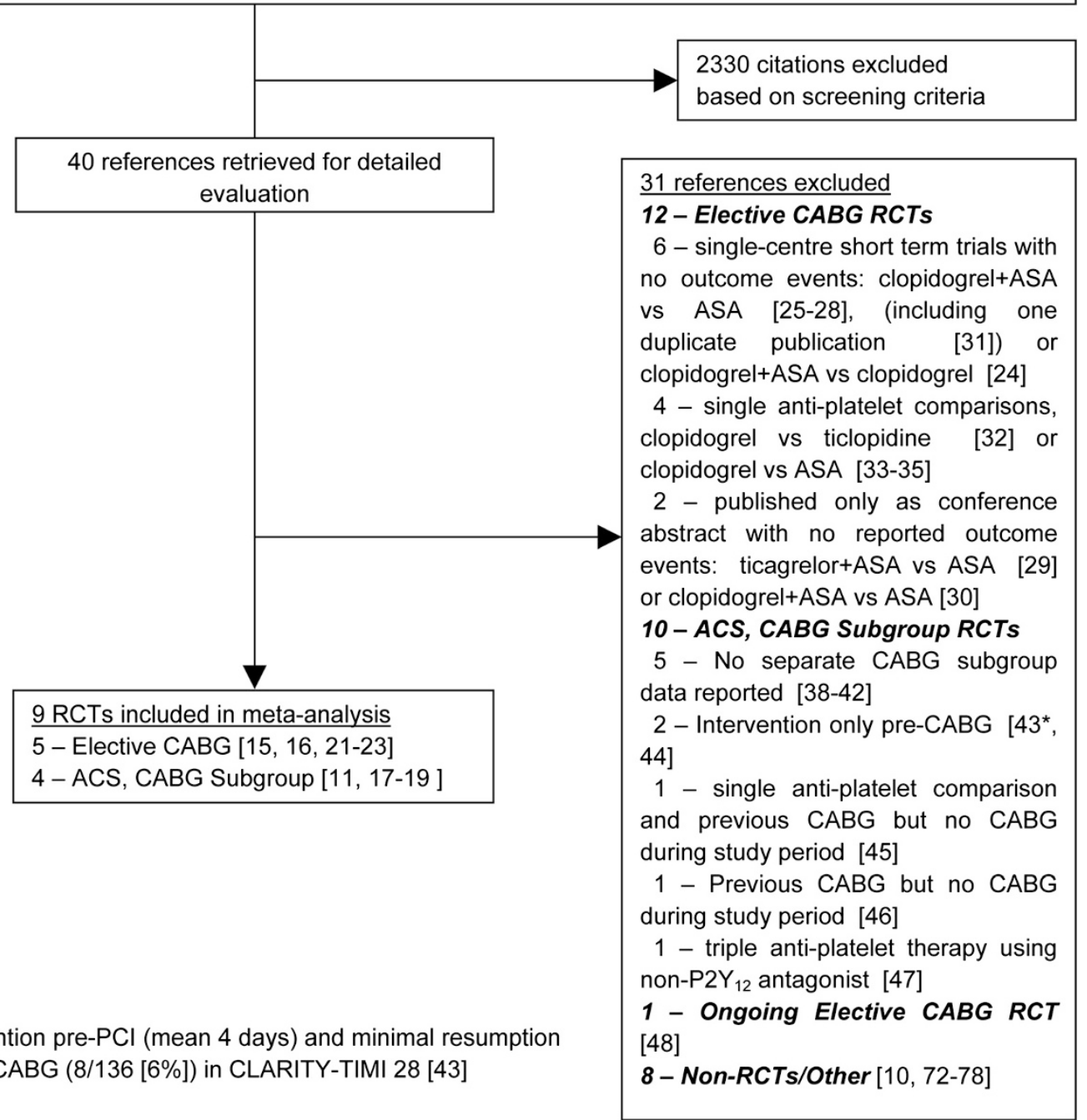

${ }^{*}$ Short term intervention pre- $\mathrm{PCl}$ (mean 4 days) and minimal resumption of study drug post CABG (8/136 [6\%]) in CLARITY-TIMI 28 [43]

Fig. 1 Search strategy and trial flow. Flow chart for the systematic review and meta-analysis showing the search strategy, and the number of studies retained and number of studies excluded with reason for exclusion at each stage of the study selection process [72-78]

reported, otherwise all major bleeding). The primary analysis included all patients in an intention to treat analysis. Prespecified subgroup analyses were conducted comparing 1) dual vs single antiplatelet therapy trials in elective CABG patients, to 2) dual vs single antiplatelet therapy trials in ACS patients who underwent CABG, to 3) higher intensity vs lower intensity dual antiplatelet trials in ACS patients who underwent CABG. We planned to also conduct a supplementary "on treatment" analysis including only patients who were actually continued on study drugs post-operatively, but these data were only available for one outcome (mortality) for one trial [11]. All meta-analyses were performed using Review Manager (RevMan version 5.2; Cochrane Collaboration, Oxford, UK) by one of the 
authors (JOF). Random effects models [12] which incorporate between-trial heterogeneity and give wider and more conservative confidence intervals $(\mathrm{CI})$ when heterogeneity is present were used for all analyses. Statistical heterogeneity among trials was assessed using $I^{2}$, defined as the percentage of total variability across studies attributable to heterogeneity rather than chance, and using published guidelines for low $\left(I^{2}=25 \%-49 \%\right)$, moderate $\left(I^{2}=50 \%\right.$ $74 \%)$ and high $\left(I^{2} \geq 75 \%\right)$ heterogeneity [13]. Risk ratios (RR) were used to pool outcomes with a two-sided significance level of $5 \%$. Individual trial and summary results are reported with $95 \%$ CIs. Differences between pooled RRs were evaluated using $\mathrm{z}$ tests. To assess for publication bias, a funnel plot comparing effect measure for the primary outcome of mortality to study precision was examined for evidence of asymmetry. Further more formal statistical testing for funnel plot asymmetry was not carried out due to the low number of RCTs meeting inclusion criteria $(<10)$ which would result in low statistical power to distinguish chance from real asymmetry [14].

We contacted authors of included trials to clarify outcome data when required. Authors of one trial provided the numbers of patients who sustained myocardial infarctions and informed us that rates of stroke were not measured [15]. For the remainder we were informed that no additional data were available [11, 16-18]. For two ACS trials only the composite outcome of either cardiovascular [19] or all-cause mortality [18], MI, and stroke were reported for the subgroup of patients who underwent CABG. Authors of one of these trials provided individual event rates [19]. For the other trial, we estimated all-cause mortality, MI, and stroke rates assuming the same overall ratios of the separate outcomes to the composite outcome for each randomized group as reported in the main trial publication [20].

\section{Results}

The initial search strategy yielded 2148 citations from MEDLINE and EMBASE, and 222 citations from Cochrane, of which 40 were retrieved for full text review. Nine RCTs met inclusion criteria (Fig. 1) [11, 15-19, 21-23]. Details regarding excluded RCTs are provided in Additional file 1: Table S1. In brief, RCTs in patients post elective CABG were excluded if no outcome events occurred or were reported [24-30] (including duplicate publication [31]) or single anti-platelet therapies were used in both randomized groups [32-35] (including duplicate publications [36, 37]). RCTs enrolling patients with ACS were excluded if no separate outcome data was available for the subgroup of patients who underwent CABG (CHARISMA [38], DISPERSE-2 [39], COMMIT [40], TRILOGY ACS [41], and JUMBO-TIMI 26 [42]), patients were not treated with dual-antiplatelet therapy post CABG (CLARITY-TIMI 28 [43] and CURRENT
OASIS 7 [44]), trials reported only on patients previously treated with CABG but not during the study period (CAPRIE [45] and PLATO [46]); or patients were randomized to a non-P2Y $\mathrm{Y}_{12}$ antagonist (TRACER [47]). One RCT in elective CABG patients was ongoing [48].

\section{Description of Included Studies and Quality Assessment}

Table 1 provides details of the trials including baseline patient characteristics. Of the 9 included RCTs, five were single- $[15,16,22,23]$ or two-centre [21] RCTs that enrolled patients post elective CABG and compared clopidogrel plus ASA to ASA alone. One trial specified that ASA was not held pre-operatively [21]. ASA and clopidogrel were restarted post-operatively when chest tube bleeding was no longer significant, typically within 2448 h. Patients were randomized either pre- [16] or post$[15,21,22]$ operatively. In one trial [23], patients were randomized on postoperative day 4 while on aspirin to clopidogrel add on but only if found to be aspirin resistant on aggregometry-based assessment.

The other four RCTs were all large multicentre trials enrolling patients with ACS that reported data separately for the subgroup of patients who underwent CABG [11, 17-19]. Of the ACS trials, 2 compared clopidogrel plus ASA to ASA alone $[3,20]$, and 2 compared higher intensity dual anti-platelet therapy with either ticagrelor [5] or prasugrel [4] plus ASA vs clopidogrel plus ASA. CREDO [20] enrolled patients who were referred for coronary angiography with symptomatic coronary artery disease (angina pectoris, positive stress test, or dynamic electrographic changes). CURE [3] enrolled patients with acute ischemic symptoms and either electrographic changes and/or elevation of cardiac enzymes to indicate myocardial necrosis, but excluded patients with ST elevation. Both PLATO [5] and TRITON-TIMI 38 [4] had similar inclusion criteria and allowed patients with either ST depression or ST elevation ACS. In TRITON-TIMI 38 [4] the coronary anatomy had to be defined and suitable for percutaneous coronary intervention (PCI) before randomization, hence a smaller percentage of patients progressed to CABG in this trial. In three of the included ACS trials [3-5], ASA and blinded second anti-platelet therapies were started shortly after presentation, whereas for CREDO [20] both randomized groups received dual anti-platelet therapy with clopidogrel for the first 28 days and then the control group received placebo for the remainder of the 1 year treatment period. For patients subsequently requiring $\mathrm{CABG}$, the second anti-platelet therapy or corresponding placebo was typically held between 1 and 7 days pre-operatively, and then re-started post-operatively in the majority (62-76 \%) of patients (Table 1) [11, 17, 19]. For CURE [19] and CREDO [18] outcome data was provided for all patients who underwent CABG. For PLATO outcome data were provided 
Table 1 Trial and Baseline Patient Characteristics, and Interventions

\begin{tabular}{|c|c|c|c|c|c|c|c|c|c|}
\hline & \multicolumn{5}{|c|}{ Patients Randomised Post Elective CABG } & \multicolumn{4}{|c|}{ Patients Randomized with ACS or symptomatic CAD - CABG Subgroup } \\
\hline & $\begin{array}{l}\text { Clopidogrel } 300 \\
\text { then } 75 \mathrm{mg} / \mathrm{d} \\
\text { vs placebo }\end{array}$ & $\begin{array}{l}\text { Clopidogrel } \\
75 \mathrm{mg} / \mathrm{d}\end{array}$ & $\begin{array}{l}\text { Clopidogrel } \\
75 \mathrm{mg} / \mathrm{d} \text { vs } \\
\text { placebo }\end{array}$ & $\begin{array}{l}\text { Clopidogrel } \\
75 \mathrm{mg} / \mathrm{d}\end{array}$ & $\begin{array}{l}\text { Clopidogrel } \\
75 \mathrm{mg} / \mathrm{d}\end{array}$ & $\begin{array}{l}\text { Clopidogrel } 300 \\
\text { then } 75 \mathrm{mg} / \mathrm{d} \text { vs } \\
\text { placebo }^{\mathrm{a}}\end{array}$ & $\begin{array}{l}\text { Clopidogrel } 300 \\
\text { then } 75 \mathrm{mg} / \mathrm{d} \\
\text { vs placebo }\end{array}$ & $\begin{array}{l}\text { Ticagrelor } 180 \text { then } \\
90 \mathrm{mg} \text { bid vs } \\
\text { Clopidogrel } 300 \text { then } \\
75 \mathrm{mg} / \mathrm{d}\end{array}$ & $\begin{array}{l}\text { Prasugrel } 60 \text { then } 10 \\
\mathrm{mg} / \mathrm{d} \text { vs Clopidogrel } \\
300 \text { then } 75 \mathrm{mg} / \mathrm{d}\end{array}$ \\
\hline $\begin{array}{l}\text { ASA Dose } \\
(\mathrm{mg} / \mathrm{d})\end{array}$ & 325 then 81 & 100 & 162 & 100 & 300 & 325 & $75-325$ & $75-100$ & $75-162$ \\
\hline Trial & Sun et al. [16] & $\begin{array}{l}\text { Gao et al. } \\
{[15]}\end{array}$ & $\begin{array}{l}\text { CASCADE } \\
{[21]}\end{array}$ & CRYSSA [22] & $\begin{array}{l}\text { Gasparovic } \\
{[23]}\end{array}$ & CREDO [18] & CURE [19] & PLATO [17] & TRITON- TIMI 38 [11] \\
\hline $\begin{array}{l}n=\mathrm{CABG} / \text { total } \\
\text { patients }\end{array}$ & $n=100 / 100$ & $n=249 / 249$ & $n=113 / 113$ & $n=300 / 300$ & $n=224 / 224$ & $n=83 / 2116$ & $n=2072 / 12562$ & $n=1261(1899) / 18624$ & $n=346(485) / 13608$ \\
\hline \multicolumn{10}{|l|}{$\begin{array}{l}\text { Trial } \\
\text { Characteristics }\end{array}$} \\
\hline $\begin{array}{l}\text { No. of } \\
\text { Centres }\end{array}$ & 1 & 1 & 2 & 1 & 1 & 99 & 428 & 862 & 707 \\
\hline $\begin{array}{l}\text { Enrolment } \\
\text { period }\end{array}$ & $\begin{array}{l}\text { Nov } 2006 \text { - } \\
\text { Feb } 2008\end{array}$ & $\begin{array}{l}\text { Dec } 2007- \\
\text { Dec } 2008\end{array}$ & $\begin{array}{l}\text { May } 2006- \\
\text { Jul } 2008\end{array}$ & $\begin{array}{l}\text { Dec } 2006- \\
\text { Oct } 2009\end{array}$ & $\begin{array}{l}\text { Jun } 2010 \text { - } \\
\text { Feb } 2013\end{array}$ & $\begin{array}{l}\text { Jun } 1999 \text { - Apr } \\
2001\end{array}$ & Dec 1998 - Sep 2000 & Oct 2006 - Jul 2008 & Nov 2004 - Jan 2007 \\
\hline $\begin{array}{l}\text { Treatment/ } \\
\text { Follow Up Post } \\
\text { Randomization }\end{array}$ & $\begin{array}{l}30(\text { all)/49 } \\
\text { (median) d }\end{array}$ & $\begin{array}{l}3 \text { months } \\
\text { (all) }\end{array}$ & $\begin{array}{l}12 \text { months } \\
\text { (all) }\end{array}$ & $\begin{array}{l}12 \text { months } \\
\text { (all) }\end{array}$ & $\begin{array}{l}6 \text { months } \\
\text { (all) }\end{array}$ & 12 months (all) & 9 months (mean) & $\begin{array}{l}224 \text { days [7.5 months] } \\
\text { (median) }\end{array}$ & 14.5 months (median) \\
\hline $\begin{array}{l}\text { Median Time } \\
\text { to CABG Post } \\
\text { Randomization }\end{array}$ & \multicolumn{5}{|c|}{ (Randomized At Time of CABG) } & $\begin{array}{l}\mathrm{n} / \mathrm{r} \text { (index CABG } \\
\text { instead of } \mathrm{PCl} \text { ) }\end{array}$ & 25.5 days (IQR 12-70.5) & $\sim 20$ days & 100 days [50] \\
\hline $\begin{array}{l}\text { Treatment/ } \\
\text { Follow Up Post } \\
\text { CABG }\end{array}$ & $\begin{array}{l}30(\text { all)/49 } \\
\text { (median) d }\end{array}$ & $\begin{array}{l}3 \text { months } \\
\text { (all) }\end{array}$ & $\begin{array}{l}12 \text { months } \\
\text { (all) }\end{array}$ & $\begin{array}{l}12 \text { months } \\
\text { (all) }\end{array}$ & $\begin{array}{l}12 \text { months } \\
\text { (all) }\end{array}$ & $\sim 12$ months (all) & $\sim 8$ months (mean) & $\begin{array}{l}\text { 200 days [6.7 months] } \\
\text { (median) }\end{array}$ & $\sim 11.2$ months (median) \\
\hline Funding & Public/ Industry & Public & $\begin{array}{l}\text { Public/ } \\
\text { Industry }\end{array}$ & $n / r$ & $n / r$ & Industry & Industry & Industry & Industry \\
\hline Patients & $n=99$ & $n=224$ & $n=113$ & $n=300$ & $n=219$ & $n=83$ & $n=2072$ & $n=1261$ & $n=346$ \\
\hline $\begin{array}{l}\text { Mean Age } \\
\text { (years) }\end{array}$ & 65 & 59 & 67 & 59 & 65 & 61 & 64 & 64 & 61 \\
\hline$\%$ Male & 90 & 83 & 89 & 74 & 75 & 74 & 70 & 79 & 77 \\
\hline BMI & 31 & 26 & 28 & 26 & 29 & 29 & & 27 & $\mathrm{n} / \mathrm{r}\left(28^{\mathrm{b}}\right)$ \\
\hline Diabetes & $35 \%$ & $40 \%$ & $29 \%$ & $0 \%(\mathrm{excl})$ & $38 \%$ & $22 \%$ & $27 \%$ & $32 \%$ & $28 \%$ \\
\hline Hypertension & $70 \%$ & $59 \%$ & $50 \%$ & $46 \%$ & $96 \%$ & $75 \%$ & $61 \%$ & $68 \%$ & $64 \%$ \\
\hline Smoker & $\begin{array}{l}59.6 \% \\
\text { (current/ } \\
\text { former) }\end{array}$ & $\begin{array}{l}55.8 \% \\
\text { (history of) }\end{array}$ & $13.2 \%$ & $n / r$ & $36 \%$ & $\begin{array}{l}33 \% \text { (within } \\
1 \text { year) }\end{array}$ & $64.5 \%$ (current /former) & $31.2 \%$ & $\mathrm{n} / \mathrm{r}\left(38 \%^{\mathrm{b}}\right)$ \\
\hline COPD & & & & $n / r$ & & $n / r$ & & & $8.1 \%$ \\
\hline Dyslipidemia & $76 \%$ & $38 \%$ & $88 \%$ & $56 \%$ & $96 \%$ & $71 \%$ & $n / r$ & $54 \%$ & $\mathrm{n} / \mathrm{r}\left(56 \%{ }^{\mathrm{b}}\right)$ \\
\hline
\end{tabular}


Table 1 Trial and Baseline Patient Characteristics, and Interventions (Continued)

\begin{tabular}{|c|c|c|c|c|c|c|c|c|c|}
\hline Prev Ml & $39 \%$ & $47 \%$ & $n / r$ & $36 \%$ & $n / r$ & $37 \%$ & $36 \%$ & $20 \%$ & $n / r\left(18 \%^{b}\right)$ \\
\hline Prev stroke/TIA & $5.1 \%$ & $4.9 \%$ & $n / r$ & $n / r$ & $n / r$ & $n / r$ & $3.9 \%$ & $3.9 \% / 3.1 \%$ & $7.8 \%$ \\
\hline Periph Vasc Dz & $5.1 \%$ & $n / r$ & $n / r$ & $n / r$ & $n / r$ & $6.2 \%$ & $9.7 \%$ & $7.6 \%$ & $7.0 \%$ \\
\hline $\begin{array}{l}\text { Chronic } \\
\text { Renal Disease }\end{array}$ & $\begin{array}{l}\text { excl } \mathrm{Cr}>130 \\
\mu \mathrm{M}\end{array}$ & $n / r$ & $n / r$ & $\begin{array}{l}\text { excl } \mathrm{Cr} \\
>177 \mu \mathrm{M}\end{array}$ & $n / r$ & $n / r$ & $n / r$ & $4.8 \%$ & $\begin{array}{l}\mathrm{n} / \mathrm{r}(11 \% \mathrm{CrCl}<60 \\
\left.\mathrm{mL} / \mathrm{min}^{\mathrm{b}}\right)\end{array}$ \\
\hline Mean LVEF & $n / r$ & $60 \%$ & & $54 \%$ & $54 \%$ & $53 \%$ & & & \\
\hline $\mathrm{CHF}$ & & $0 \%($ excl) & $20.3 \%$ & $n / r$ & $n / r$ & $7.3 \%$ & & $4.1 \%$ & $10.7 \%$ \\
\hline \multirow{2}{*}{$\begin{array}{l}\text { Severe LV } \\
\text { dysfunction }\end{array}$} & $38 \%(G r 3$ LV) & $0 \%($ excl) & $n / r$ & $n / r$ & $n / r$ & $n / r$ & Excluded & & $3.9 \%(E F \leq 30 \%)$ \\
\hline & 1 \% (Gr 4 LV) & & & & & & & & \\
\hline Previous $\mathrm{PCl}$ & $n / r$ & $13 \%$ & & $16 \%$ & $n / r$ & $17 \%$ & $7.4 \%$ & $10 \%$ & $n / r$ \\
\hline Previous CABG & $n / r$ & $0 \%($ excl) & $0 \%($ excl) & $n / r$ & $n / r$ & $8.5 \%$ & $4.6 \%$ & $1.5 \%$ & $2.9 \%$ \\
\hline $3 \mathrm{VD}$ & $54 \%$ & & & $n / r$ & $77 \%$ & $n / r$ & & & \\
\hline LM & $24.2 \%$ & & & $n / r$ & $48 \%$ & $n / r$ & & & \\
\hline ST depression & & & & & & & $54.2 \%$ & & \\
\hline ST elevation & & & & & & & $2.7 \%$ & $33.0 \%$ (persistent) & \\
\hline Abnormal ECG & & & & & & & $95.2 \%$ & & \\
\hline Diagnosis: UA & & & & & & & $73.9 \%$ & & $64.1 \%$ (UA/NSTEMI) \\
\hline Diagnosis: Ml & & & & & & & $26.1 \%$ (all NSTEMI) & & $35.9 \%$ (STEMI) \\
\hline $\begin{array}{l}\text { Abnormal } \\
\text { ECG/enzymes }\end{array}$ & & & & & & & $97.7 \%$ & & \\
\hline \multicolumn{10}{|l|}{ CABG } \\
\hline $\begin{array}{l}\% \text { Off-pump } \\
\text { CABG }\end{array}$ & $0 \%$ & $58.0 \%$ & $3.6 \%$ & $100 \%$ & $0 \%$ & & & & \\
\hline $\begin{array}{l}\% \text { arterial } \\
\text { conduits }\end{array}$ & $100 \%$ & $100 \%$ & $100 \%$ & $100 \%$ & $93 \%$ & & & & \\
\hline \multirow{3}{*}{$\begin{array}{l}\text { Grafts or } \\
\text { adiseased } \\
\text { vessels }\end{array}$} & 4.0 & 3.1 & $3.5 \pm 0.7$ & $3.2 \pm 0.6$ & $n / r$ & & & $1-2(31 \%)$ & ${ }^{a} 1$ (14.4\%) \\
\hline & & & & & & & & $3-4(60 \%)$ & ${ }^{\mathrm{a}} 2(61.5 \%)$ \\
\hline & & & & & & & & $\geq 5$ (8 \%) & ${ }^{a} 3(20.5 \%)$ \\
\hline $\begin{array}{l}\text { Median (IQR) } \\
\text { days to CABG } \\
\text { (all) }\end{array}$ & & & & & & & $25.5(12-70.5)$ & $\sim 20$ & $100(36)$ \\
\hline CABG pre-d/c & & & & & & & $49 \%$ & $57 \%$ & $4.3 \%$ \\
\hline $\begin{array}{l}\text { Median (IQR) } \\
\text { days to CABG } \\
\text { pre-d/c }\end{array}$ & & & & & & & 13 (8-21) vs 12 (8-19) & & \\
\hline CABG post-d/c & & & & & & & $51 \%$ & $43 \%$ & $95.7 \%$ \\
\hline
\end{tabular}


Table 1 Trial and Baseline Patient Characteristics, and Interventions (Continued)

\begin{tabular}{|c|c|c|c|}
\hline $\begin{array}{l}\text { Median (IQR) } \\
\text { days to CABG } \\
\text { post } d / c\end{array}$ & \multicolumn{3}{|c|}{$67.5(38-141)$ vs 73 (36-129) } \\
\hline $\begin{array}{l}\text { Days off study } \\
\text { drug before } \\
\text { CABG }\end{array}$ & $17(9-33)$ & $\begin{array}{l}\leq 2 d(30.1 \%) 3-5 d \\
(43.8 \%)>5(26.1 \%)\end{array}$ & $\begin{array}{l}\leq 2 d(25.1 \%) 3-5 d \\
(29.0 \%)>5(45.4 \%)\end{array}$ \\
\hline $\begin{array}{l}\text { Restarted } \\
\text { treatment post } \\
\text { CABG }\end{array}$ & $\begin{array}{l}76.1 \% \text { ( } 66 \text { never } \\
\text { discontinued }+1451 \\
\text { resumed/1928; } 78 \text { data } \\
\text { unavailable) }\end{array}$ & $66.4 \%$ & $\begin{array}{l}61.8 \% \text { (214/346); additional } \\
21 / 173 \text { prasugrel and 16/173 } \\
\text { clopidogrel patients resumed } \\
\text { open label clopidogrel }\end{array}$ \\
\hline \multirow{3}{*}{$\begin{array}{l}\text { Days off study } \\
\text { drug after } \\
\text { CABG }\end{array}$} & \multirow[t]{3}{*}{$10(6-25)$} & $<7 d(35.9 \%)$ & \multirow[t]{3}{*}{$n / r$} \\
\hline & & 7-14(16.8 \%) & \\
\hline & & $>14 d(10.0 \%)$ & \\
\hline
\end{tabular}

${ }^{a}$ In CREDO, both groups receive clopidogrel $75 \mathrm{mg} /$ day for 28 days before control group changed to placebo from day 29 through 12 months

${ }^{\mathrm{b}}$ Proportion of all 13,608 randomized patients when data not provided for CABG subgroup in TRITON-TIMI 38

Abbreviations: $A C S$ acute coronary syndrome, $A S A$ acetylsalicylic acid (aspirin), BMI body mass index, CABG coronary artery bypass grafting, CAD coronary artery disease, CHF congestive heart failure, COPD chronic

Abbrevitivi obstructive pula

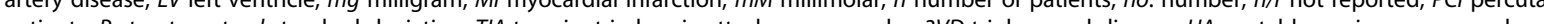


only for the 1261 of 1899 patients that underwent CABG who received study drug within 7 days prior to the procedure [17]. For TRITON-TIMI 38 all outcome data were only provided for the 346 of 485 randomized patients that underwent CABG who received at least one dose of study drug prior to the procedure [11]; additional outcome data on all randomized patients that underwent CABG were provided in a FDA presentation [49].

For all trials, enrolled patients had a mean age around 60 years old, were predominantly male, and had the expected prevalence of various coronary risk factors (Table 1). $18-47 \%$ of patients had previous myocardial infarction, and a small percentage (3-8 \%) had previous stroke. A small percentage also had previously been treated with PCI or CABG. Patients with heart failure or severe left ventricular dysfunction were generally excluded. Some trials used off-pump surgery, and all patients received multiple grafts with at least one arterial conduit.

As shown in Table 1, in the 5 RCTs enrolling elective CABG patients, all patients were enrolled at the time of CABG and followed up for 12 months in two trials [21, 22], 6 months in one trial [23], 3 months in one trial [15], and a minimum of 30 days (median 49 days) in the fifth trial [16]. In 3 of the 4 RCTs enrolling ACS patients, CABG occurred at a median time of 20-100 days post-randomization $[17,19,50]$ and patients were followed for a median of 6.7 to 11.2 months post CABG. Time to CABG and follow up duration was similar between groups in each trial. The fourth ACS trial enrolling patients expected to require PCI did not specifically report time to CABG but included only patients who were treated with CABG instead of PCI at study enrolment implying treatment shortly after randomization, and followed all patients for 12 months post randomization [18]. For all trials only clinical outcomes that occurred post CABG were included.

Study quality was relatively high (Table 2). Allocation was concealed in all trials except for one single-centre trial where it was unclear [15], and all studies except for three single-centre trials $[15,22,23]$ blinded participants using placebos. All trials used intention-to-treat analysis, were not stopped early for benefit, and had $<5 \%$ (and for the large multi-centre trials $\leq 0.1 \%$ ) of randomized patients with missing outcome data.

\section{Quantitative Data Synthesis}

All-Cause Mortality (Fig. 2): Pooling data from all RCTs, there was no difference in all-cause mortality (RR 0.68 , $95 \%$ CI $0.43-1.08, p=0.10$ ) with some heterogeneity $\left(I^{2}=39 \%\right)$. The clopidogrel plus ASA vs ASA RCTs showed no difference in all-cause mortality for either the elective CABG (RR 0.56, $95 \%$ CI 0.18-1.67, $p=0.29$ ) or the ACS CABG subgroups (RR 1.18, $95 \%$ CI $0.83-$ $1.66, p=0.36$ ). However, the ticagrelor or prasugrel vs clopidogrel RCTs showed significantly lower risk for allcause mortality (RR $0.49,95 \%$ CI $0.33-0.71, p=0.0002$ ). There was no heterogeneity within any of the subgroups $\left(I^{2}=0 \%\right)$. The differences between the clopidogrel plus ASA vs ASA elective CABG and ACS subgroups (either individually or combined), and the ticagrelor or prasugrel vs clopidogrel subgroup results were statistically significant (interaction p-value 0.002-0.007). Visual inspection of the funnel plot showed no evidence of asymmetry (data not shown).

Other Clinical Outcomes: Neither dual vs single nor higher-intensity vs lower-intensity dual anti-platelet therapy resulted in decreased myocardial infarction (RR $0.91,95 \%$ CI $0.69-1.20, p=0.52$; Fig. 3a) or stroke (RR 1.10, $95 \%$ CI $0.75-1.62, p=0.61$; Fig. $3 b$ ) with similar non-significant treatment effects in the dual vs single anti-platelet and higher-intensity vs lower-intensity DAPT subgroups $\left(I^{2}=0 \%\right)$. Likewise the composite outcome of death from cardiovascular causes (all-cause mortality for CRYSSA [22] and CREDO [18]), myocardial infarction, and stroke (only cardiovascular death and myocardial infarction for Gao 2010 [15]) remained non-significant (Fig. 3c): RR 0.86, 95 \% CI $0.73-1.03, p=0.10$, with no differences in results between subgroups $\left(I^{2}=0 \%\right)$.

Table 2 Quality assessment of included randomized controlled trials

\begin{tabular}{llllll}
\hline Trial & Blinded & Concealed allocation & $\begin{array}{l}\text { Intention to treat } \\
\text { analysis }\end{array}$ & $\begin{array}{l}\text { Not stopped early } \\
\text { for benefit }\end{array}$ & $\begin{array}{l}\text { < } 5 \text { Randomized Patients with } \\
\text { Missing Outcome Data }\end{array}$ \\
\hline CURE $[3,19]$ & Yes & Yes (central randomization) & Yes & Yes & Yes (0.1\%: 13/12,562 overall; 0 \% of CABG) \\
PLATO [5, 17] & Yes & Yes (central randomization) & Yes & Yes & Yes (0.03\%: 5/18,624 overall) \\
TRITON-TIMI 38 [4, 11] & Yes & Yes (central randomization) & Yes & Yes & Yes (0.1\%: 14/13,608 overall) \\
CREDO [18, 20] & Yes & Yes & Yes & Yes & Yes (0 \%) \\
CRYSSA [22] & No & Yes & Yes & Yes & Yes (0.3\%: 1/300) \\
CASCADE [21] & Yes & Yes & Yes & Yes & Yes (0 \%) \\
Gao 2010 [15] & No & Unclear & Yes & Yes & Yes (3.7\%: 9/249) \\
Sun 2010 [16] & Yes & Yes & Yes & Yes & Yes (1.0 \%: 1/100) \\
Gasparovic 2014 [23] & No & Yes & Yes & Yes & Yes $(2.2 \%: 5 / 224)$ \\
\hline
\end{tabular}




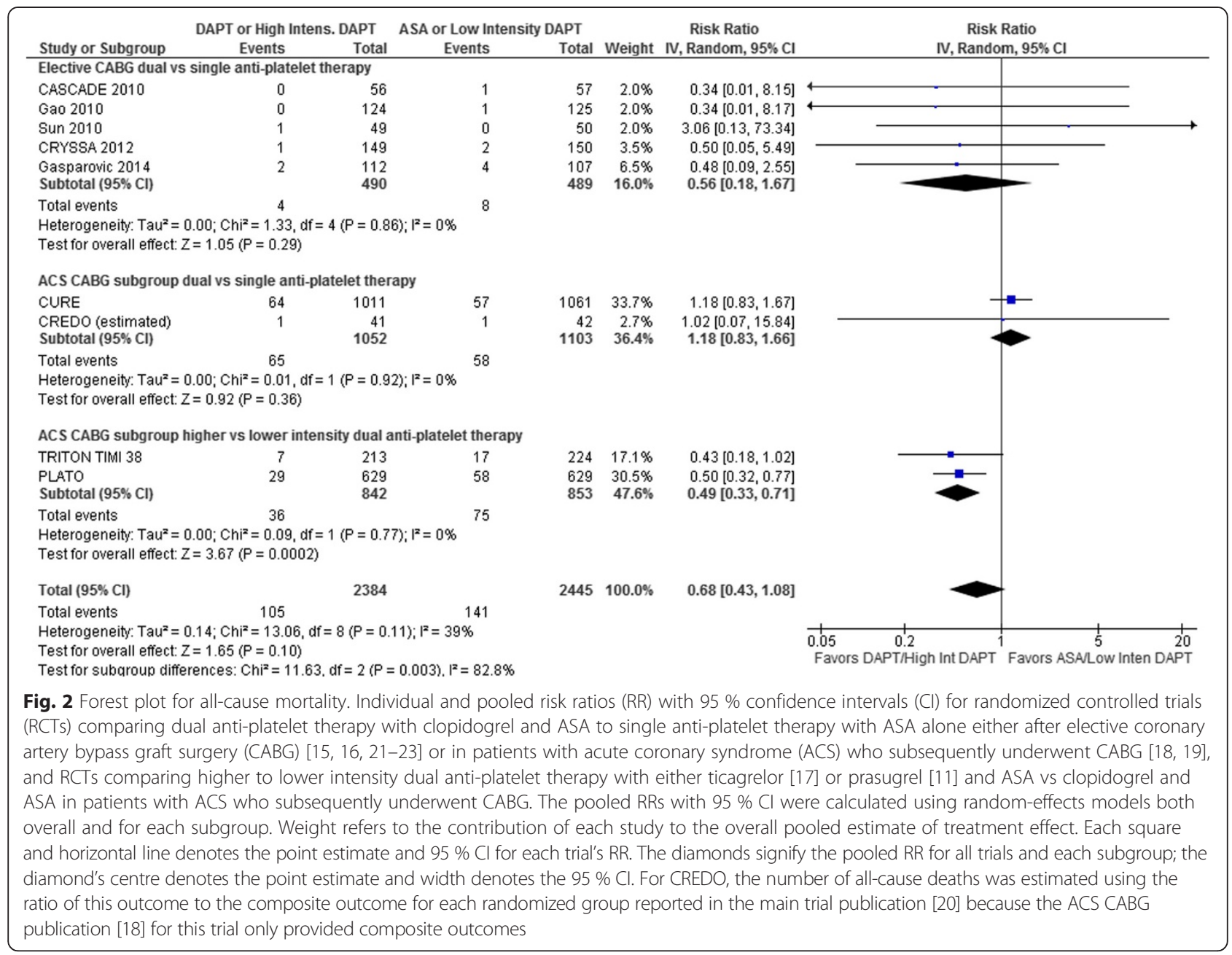

Bleeding: The clopidogrel plus ASA vs ASA trials that reported bleeding used CURE trial [19, 21, 22], Bleeding Academic Research Consortium (BARC) Bleeding Definitions [51] Type 3-5 [23] or similar [16] criteria for major bleeding and reported events that were either non-CABG related [16, 21-23] or more than 7 days post CABG [19]. The higherintensity vs lower-intensity DAPT trials reported bleeding using TIMI criteria and included both CABG-related and non-CABG-related bleeding. One of these trials specifically stated that "nearly all bleeding events occurred within $24 \mathrm{~h}$ post-CABG" [17]. Overall, major bleeding was not significantly increased (RR 1.31, 95 \% CI 0.81-2.10, $p=0.27$; Fig. 4) with some heterogeneity $\left(I^{2}=42 \%\right)$ but no differences between subgroup results. The heterogeneity was due entirely to the significantly higher bleeding rate reported for TRITON-TIMI $38\left(I^{2}=0 \%\right.$ when the results of this trial are excluded).

\section{Discussion}

The results from this analysis suggest that DAPT resumption with higher intensity $\mathrm{P}^{2} \mathrm{Y}_{12}$ antagonists (prasugrel or ticagrelor), but not clopidogrel reduces all-cause mortality in ACS patients who have undergone CABG. However, these results are based on post-randomization subsets from single RCTs where DAPT was initiated prior to $C A B G$, with the intention of continuing therapy for one year post revascularization. Although it would have been invaluable to compare the outcomes in patients who continued DAPT vs. those in whom therapy was not resumed post-CABG, these data were not available. Likewise, there are no RCTs wherein ACS patients were randomized to receive DAPT vs. ASA following CABG. Finally, the number of patients enrolled in elective CABG RCTs was considerably smaller, and the pooled results of these RCTs comparing exclusively clopidogrel plus ASA to ASA alone post operatively demonstrated no differences in outcomes. 


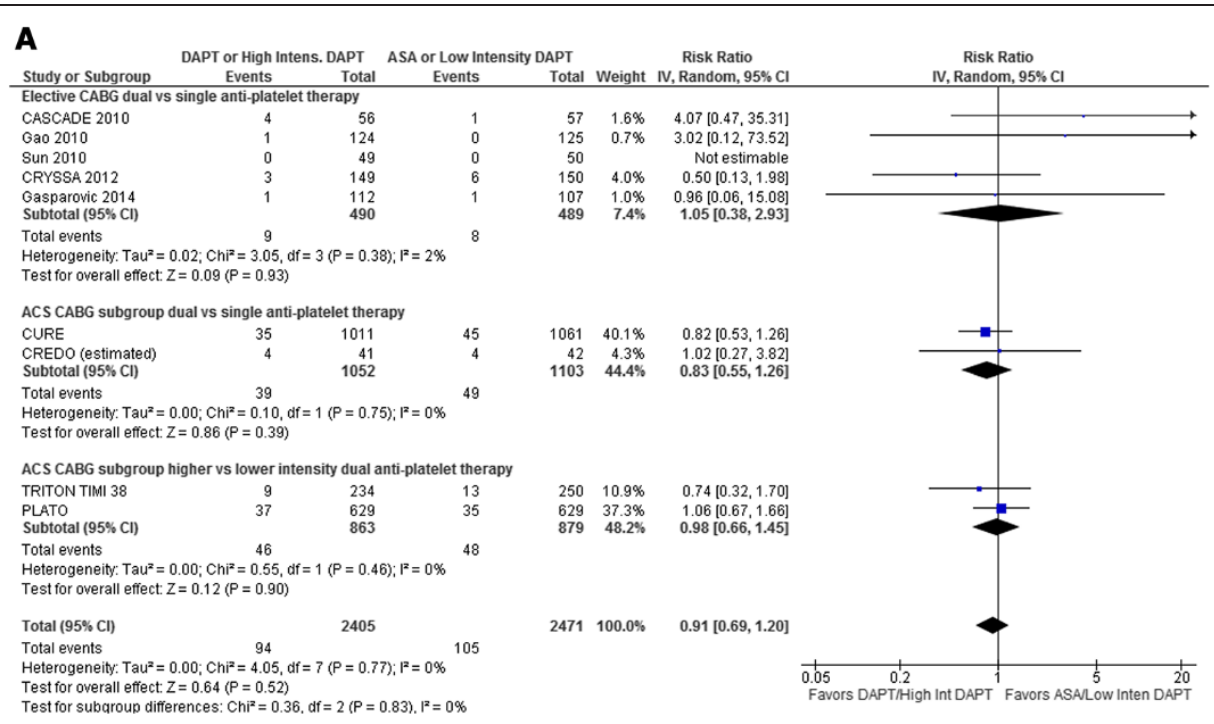

B

DAPT or High Intens. DAPT ASA or Low Intensity DAPT Risk Ratio

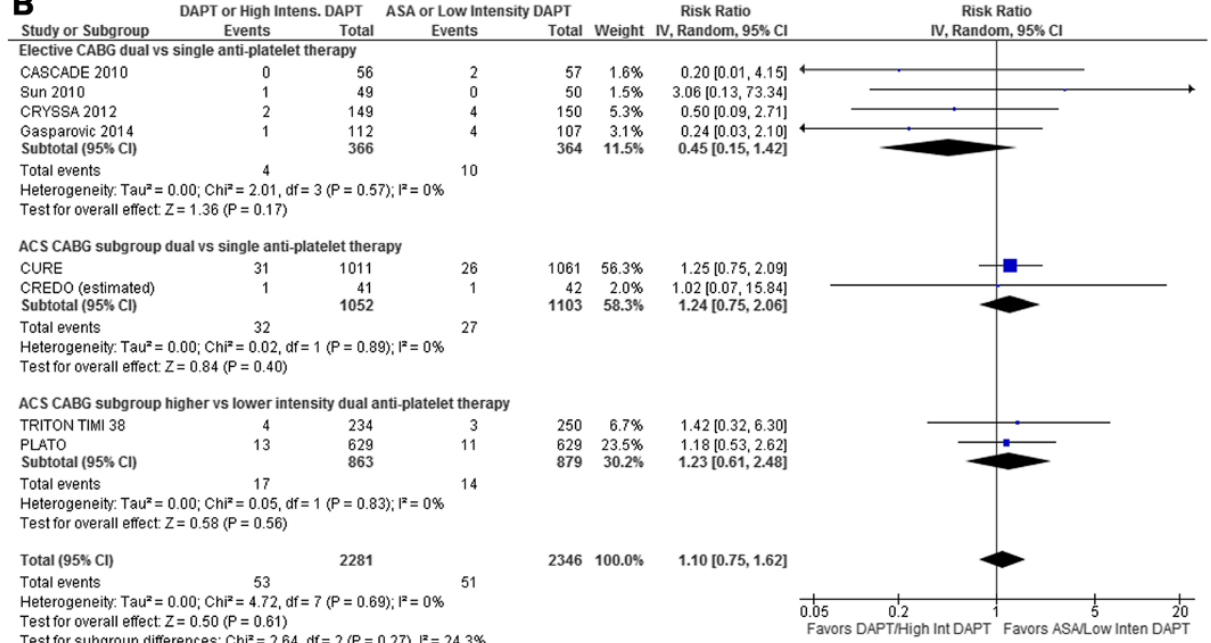

Test for subaroup differences: $\mathrm{Ch}^{2}=2.64, \mathrm{df}=2(\mathrm{P}=0.27), \mathrm{F}^{2}=24.3 \%$

C

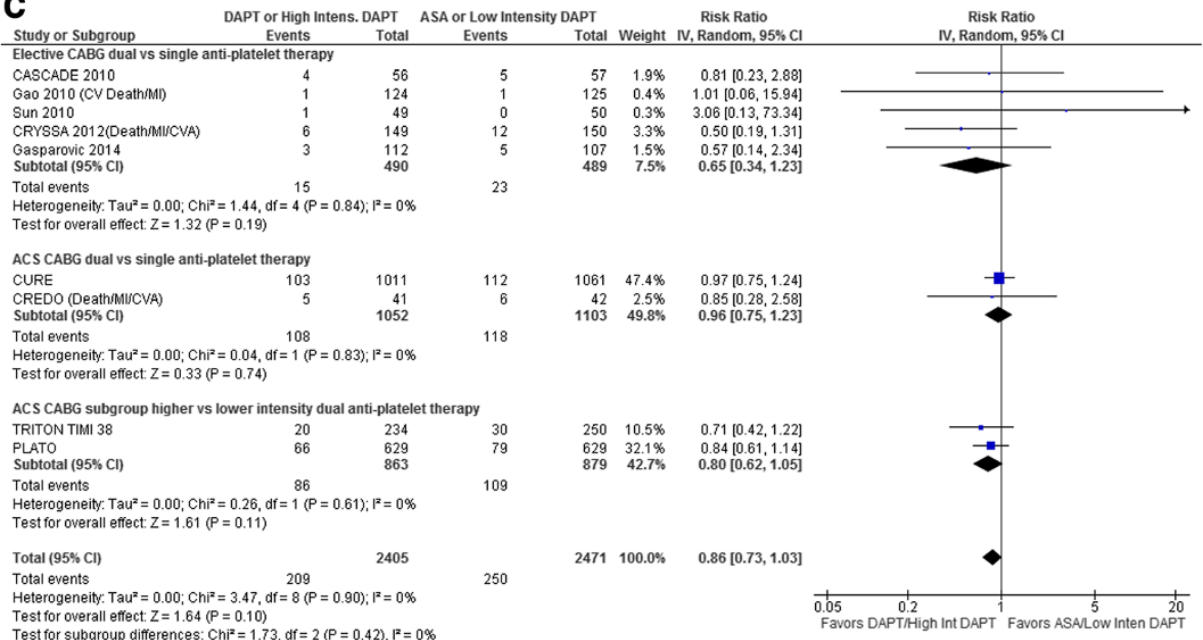

Fig. 3 (See legend on next page.) 
(See figure on previous page.)

Fig. 3 Forest plot for (a) myocardial infarction, (b) stroke, (c) composite outcome including cardiovascular mortality, myocardial infarction, and stroke. Individual and pooled risk ratios (RR) with $95 \%$ confidence intervals (CI) for randomized controlled trials (RCTs) comparing dual anti-platelet therapy with clopidogrel and ASA to single anti-platelet therapy with ASA alone either after elective coronary artery bypass graft surgery $(C A B G)[15,16,21-23]$ or in patients with acute coronary syndrome (ACS) who subsequently underwent CABG $[18,19]$, and RCTs comparing higher to lower intensity dual anti-platelet therapy with either ticagrelor [17] or prasugrel [11] and ASA vs clopidogrel and ASA in patients with ACS who subsequently underwent CABG. The pooled RRs with $95 \% \mathrm{Cl}$ were calculated using random-effects models both overall and for each subgroup. Weight refers to the contribution of each study to the overall pooled estimate of treatment effect. Each square and horizontal line denotes the point estimate and $95 \% \mathrm{Cl}$ for each trial's RR. The diamonds signify the pooled RR for all trials and each subgroup; the diamond's centre denotes the point estimate and width denotes the $95 \% \mathrm{Cl}$. For CREDO, the number of myocardial infarctions and strokes was estimated using the ratio of this outcome to the composite outcome for each randomized group reported in the main trial publication [20] because the ACS CABG publication [18] for this trial only provided composite outcomes. For the composite outcome reported in Panel C, only all-cause mortality was available for CRYSSA 2012 [22] and CREDO [18], and only cardiovascular death and myocardial infarction for Gao 2010 [15]

Among the higher-intensity $\mathrm{P} \mathrm{Y}_{12}$ antagonist RCTs, it is important to highlight that in TRITON-TIMI 38 prasugrel was only initiated after the coronary anatomy was defined and PCI was planned [11]. The trial was not intended to recruit patients destined for CABG, although in the minority of patients who did undergo CABG, the prasugrel group yielded a significant reduction in mortality. Prasugrel was associated with an increased risk of major bleeds which was primarily CABG related. A subsequent analysis by the trial authors indicated that prasugrel-treated patients received higher platelet but not red blood cell transfusions [50].

Ticagrelor is a novel $\mathrm{P}_{2} \mathrm{Y}_{12}$ antagonist, with a reversible mechanism of action. It provides more effective and

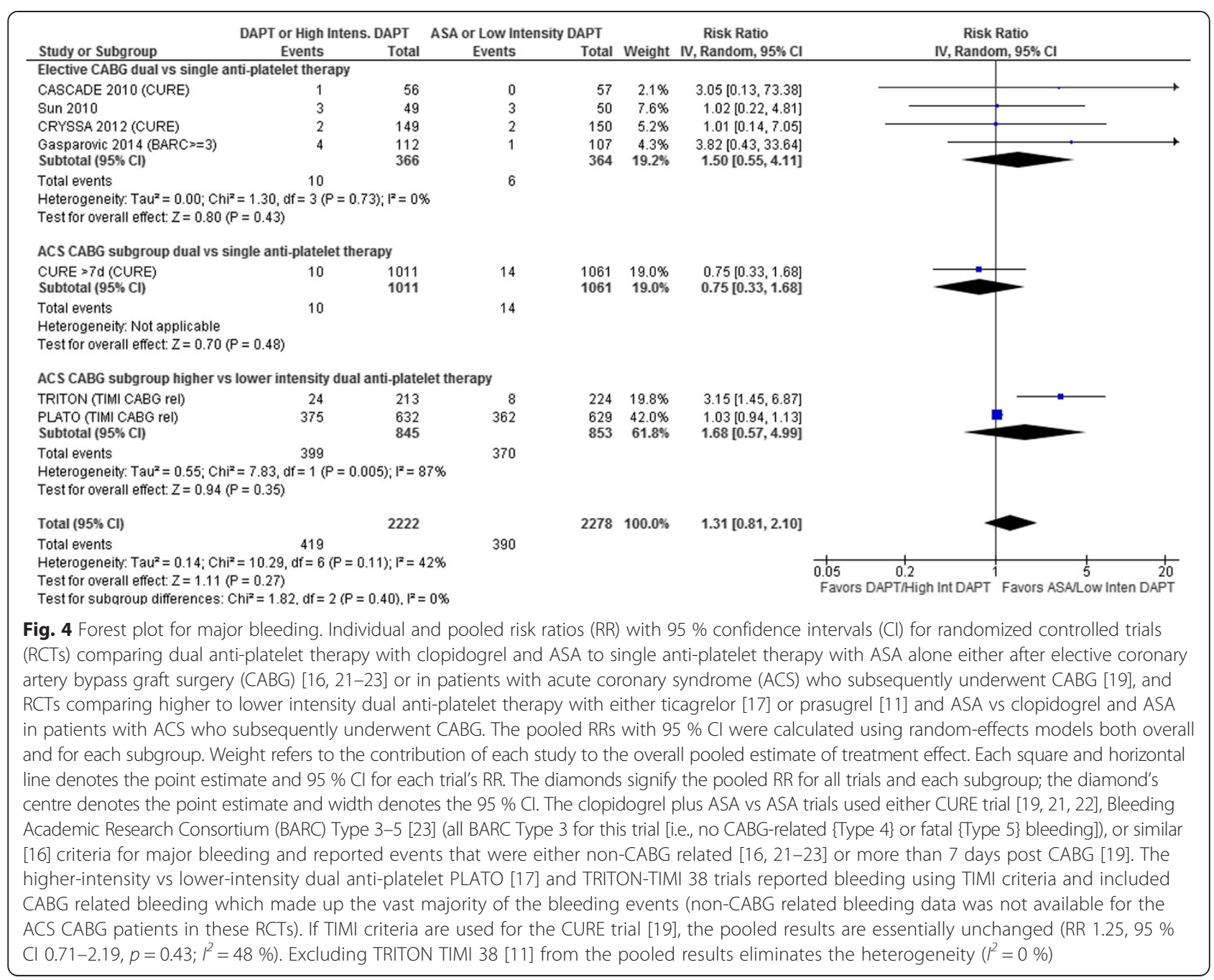


reliable inhibition of platelet activity compared to clopidogrel [52], and recent data suggest that it may also have a unique pleiotropic effect to augment adenosine bioavailability [53]. In the PLATO trial, randomization for 1-year to DAPT with ticagrelor vs. clopidogrel reduced all-cause mortality in the entire cohort by $20 \%$; the magnitude of benefit was particularly striking in those who underwent CABG (of whom approximately $66 \%$ were restarted on study drug), where an approximate $50 \%$ reduction in mortality was observed [17]. Interestingly, CABG related major bleeding, defined by various criteria was not different between ticagrelor vs. clopidogrel arms, and neither were the rate of transfusion or mean chest tube drainage. However, non-CABG related major bleeds were slightly higher in the ticagrelor vs. clopidogrel treated patients in all patients [5]. (Non-CABG related major bleed data was unfortunately unavailable for the CABG subset [17]). Since non-CABG related bleeding is likely the safety outcome of interest outside of the immediate perioperative period, surgeons must weigh the bleeding risk relative to the major reduction in all-cause mortality in choosing whether or not to resume DAPT with ticagrelor [54]. Recent data suggest that the adjusted hazard ratio for bleeding with ticagrelor does not increase with age [55].

The present analysis does not provide insight regarding what types of ACS patients are more likely to benefit from DAPT post CABG. It may be hypothesized that patients with diffuse disease (diabetes and chronic kidney disease for example), may be more likely to derive ongoing ischemic benefit by virtue of reduction in new atherothrombotic events. Likewise, analysis of benefit as a function of complexity of lesions (SYNTAX score for example) has not been conducted. Individualizing therapy based on residual platelet reactivity while on treatment which can vary widely between patients may help to better identify patients who would benefit from higher intensity anti-platelet therapy. For example, the most recently published trial included in this meta-analysis [23] attempted to do this by randomizing only patients to DAPT who still had high residual platelet reactivity while on ASA. Further studies aimed at better refining the subgroups that are more likely to derive the greatest ischemic benefit, and yield the lowest bleeding signal need to be performed.

Our systematic review and meta-analysis is the first to include both RCTs enrolling patients undergoing elective CABG and subgroups of patients presenting with ACS who subsequently require CABG. Furthermore, we also included RCTs that employed both higher- and lowerintensity dual antiplatelet therapies. Because results from these different types of RCTs may differ, we separated them into subgroups of RCTs for each analysis to highlight potential differences. Previous systematic reviews have been more restrictive either including only studies enrolling elective CABG patients [56-58], comparing lower intensity dual antiplatelet therapy with clopidogrel plus ASA to ASA [59], comparing dual or single antiplatelet therapy with clopidogrel to ASA $[60,61]$, or comparing higher- to lower-intensity dual anti-platelet therapy [62, 63]. These systematic reviews are in addition to those evaluating the use of dual anti-platelet therapy at the time of CABG [64-71]. We included all RCTs in any of these systematic reviews that met inclusion criteria for the current review.

\section{Study Limitations}

Although we used rigorous systematic review and metaanalytic methods consistent with PRISMA guidelines including a reproducible and comprehensive literature search strategy, clearly defined inclusion criteria, duplicate citation review, data abstraction, and quality assessment of individual studies, and a pre-defined analysis plan, we pooled results from studies that employed different inclusion/exclusion criteria, interventions, and follow up periods. In particular, we pooled results from trials comparing dual vs single antiplatelet therapies (clopidogrel plus ASA vs ASA) with trials using different higher intensity dual platelet therapies (using ticagrelor or prasugrel) vs lower intensity dual platelet therapies (using clopidogel). We also pooled results from trials enrolling elective CABG patients with ACS patients who were randomized to dual anti-platelet therapy groups and then subsequently required CABG. Recognizing these differences, we presented pooled results separately for each of these subgroups within each analysis. The small size of elective CABG patient trials resulted in few events highlighting the paucity of currently available data (as well as upcoming data from ongoing registered trials listed in Additional file 1: Table S1) in this specific patient population, making it difficult to assess either the benefits, in terms of reducing adverse cardiac events, or the harms, in terms of increased bleeding. Follow up duration was variable ranging from 1.5 to 12 months for the elective CABG patients trials, and 6-12 months for the trials enrolling ACS patients who subsequently required CABG. The majority of the patient data was obtained from the large multicentre trials enrolling patients with ACS in which only a subgroup of patients underwent CABG [11, 17-19], at various time points, up to a median of 100 days post randomization in one trial [50]. Although separate subgroup data for the patients treated with CABG have been reported in the ACS RCTs, the decision to undergo CABG is a post randomization event occurring at variable times post randomization. This decision can thus be influenced by randomized group resulting in potential baseline imbalances between intervention and control groups within the subgroup, though the baseline characteristics reported for the subgroups undergoing CABG were balanced in 
these trials [11, 17-19]. Furthermore in some of these trials, complete outcome data are only reported for some of the patients who underwent CABG [11, 17] and these patients may be lower risk than CABG ACS patients treated outside of clinical trials. Except for bleeding events in CURE which were reported greater than 7 days post CABG, bleeding events in the other ACS trials though reported postoperatively also included events related to the operation. For example, bleeding events in TRITON-TIMI 38 and PLATO included all post-operative events and one of these reports stated that "nearly all bleeding events occurred within 24 h post-CABG" [17]. Finally, for the subgroups of patients with acute coronary syndrome who underwent $C A B G$, we analyzed the patients on an intention to treat basis; only $62-76 \%$ of the patients in the three largest trials $[11,17,19]$ resumed dual antiplatelet therapy post operatively. Incomplete resumption of assigned treatment will reduce apparent treatment and adverse effects. Only TRITON-TIMI 38 provided on-treatment data and then only for mortality [11]. Conducting an on-treatment analysis, if these data were available for all trials, may provide better efficacy data; however, this would involve incorporating a further post-randomization event potentially leading to non-comparable groups with dissimilar baseline characteristics. For ACS patients the timing of DAPT treatment is likely more complex since when DAPT is discontinued preoperatively (to maximize the ACS benefit and to minimize bleeding) and when DAPT is resumed postoperatively (to maximize post-operative benefits) may both potentially affect outcomes.

\section{Conclusions}

Based on the available but limited RCT data, resumption of anti-platelet therapy post operatively with higher intensity DAPT (prasugrel or ticagrelor with ASA) but not lower intensity DAPT (clopidogrel and ASA) appears to reduce all-cause mortality by about $50 \%$ in patients with ACS who undergo CABG. With the caveat that the data are primarily based on retrospective subgroup analysis from single RCTs of ACS patients who progress to CABG, the net clinical benefit (efficacy vs. bleeding) appears to favour the use of ticagrelor in these patients. No significant benefits or harms were detected for DAPT after elective CABG, however, few such patients have been studied in randomized trials. The limited RCT data suggest that large prospective RCTs evaluating the use of DAPT post-CABG are urgently needed to provide more definitive guidance for clinicians.

\section{Additional file}

Additional file 1: Description of Excluded RCTs. (DOC 63 kb)

\section{Abbreviations}

ACS: Acute coronary syndrome; ASA: Acetylsalicylic acid; CABG: Coronary artery bypass graft surgery; Cl: Confidence interval; DAPT: Dual antiplatelet therapy; MI: Myocardial infarction; NSTEMI: Non-ST segment elevation myocardial infarction; PCl: Percutaneous coronary intervention; RCT: Randomized controlled trial; RR: Risk ratio; STEMI: ST-elevation myocardial infarction.

\section{Competing interests}

Dr Verma has received research grant support and/or speaker/consulting honoraria from AstraZeneca, Bayer, Boehringer Ingelheim, GlaxoSmithKline, Merck, Pfizer and Sanofi. Dr Goodman has received research grant support and/or speaker/consulting honoraria from AstraZeneca, Bristol-Myers Squibb/ Sanofi, and Eli Lilly/Daiichi-Sankyo. Dr Mehta has received research grant support and/or speaker/consulting honoraria from AstraZeneca, Boston Scientific, Eli Lilly, and Merck. Dr Ruel has received research grant support from Bristol-Myers Squibb/Sanofi. Dr M Gupta has received research grant support and/or speaker/consulting honoraria from AstraZeneca, Eli Lilly, Merck, and Bristol-Myers Squibb/Sanofi. None of the disclosures pertain to the current investigation which received no specific funding. All other authors have nothing to disclose with regard to commercial support.

\section{Authors' contributions}

SV and JOF conceived and designed the study. NG, HT and JOF acquired the data. SV, SGG, SRM, DAL, MR, MG, BY, MAO and JOF analyzed and interpreted the data. SV, NG, HT and JOF drafted the original manuscript. SV, SGG, SRM, DAL, MR, MG, BY, MAO, HT and JOF critically revised the manuscript. All authors have read and approved the final version of the manuscript. All authors agree to be accountable for all aspects of the work ensuring that questions related to the accuracy or integrity of any part of the work are appropriately investigated and resolved.

\section{Authors' information}

Not applicable.

\section{Acknowledgements}

The authors thank Professors Ge Gao and Shengshou Hu for providing additional outcome data for their trial [15], Dr Jennifer Tsang for assistance with translation, and Adrian Quan for expert assistance with the generation of the figures. SV is the Canada Research Chair in Atherosclerosis. JOF holds a Clinician Scientist Award from the Canadian Institutes of Health Research (CIHR). CIHR had no involvement in the design and conduct of this study.

\section{Author details}

${ }^{1}$ Division of Cardiac Surgery, Keenan Research Centre for Biomedical Science and Li Ka Shing Knowledge Institute of St. Michael's Hospital, Toronto, ON M5B 1W8, Canada. ${ }^{2}$ Division of Cardiology, Li Ka Shing Knowledge Institute of St. Michael's Hospital, Toronto, ON M5B 1W8, Canada. ${ }^{3}$ Division of Vascular Surgery, Keenan Research Centre for Biomedical Science and Li Ka Shing Knowledge Institute of St. Michael's Hospital, Toronto, ON M5B 1W8, Canada. ${ }^{4}$ Division of Endocrinology \& Metabolism, Keenan Research Centre for Biomedical Science and Li Ka Shing Knowledge Institute of St. Michael's Hospital, Toronto, ON M5B 1W8, Canada. ${ }^{5}$ Department of Surgery, St. Michael's Hospital, Toronto, ON M5B 1W8, Canada. ${ }^{6}$ Department of Medicine, St. Michael's Hospital, Toronto, ON M5B 1W8, Canada. ${ }^{7}$ Department of Critical Care, St. Michael's Hospital, Toronto, ON M5B 1W8, Canada. ${ }^{8}$ Department of Surgery, University of Toronto, Toronto, ON M5S 2J7, Canada. ${ }^{9}$ Department of Medicine, University of Toronto, Toronto, ON M5S 2J7, Canada.

${ }^{10}$ Interdepartmental Division of Critical Care, University of Toronto, Toronto, ON M5S 2J7, Canada. ${ }^{11}$ King Saud University, Riyadh 12372, Saudi Arabia. ${ }^{12}$ Department of Medicine, McMaster University, Hamilton, ON L8L 2X2, Canada. ${ }^{13}$ Population Health Research Institute, Hamilton Health Sciences, Hamilton, ON L8L 2X2, Canada. ${ }^{14}$ University of Ottawa Heart Institute, Ottawa, ON K1Y 4W7, Canada. ${ }^{15}$ Canadian Cardiovascular Research Network, Brampton, ON L6Z 4N5, Canada. ${ }^{16}$ The Ottawa Hospital, Ottawa, ON K1H 8L6, Canada.

Received: 4 March 2015 Accepted: 1 October 2015 Published online: 14 October 2015 


\section{References}

1. Jneid $H$, Anderson JL, Wright RS, Adams CD, Bridges CR, Casey Jr DE, et al. ACCF/AHA focused update of the guideline for the management of patients with unstable angina/non-ST-elevation myocardial infarction (updating the 2007 guideline and replacing the 2011 focused update): a report of the American College of Cardiology Foundation/American Heart Association Task Force on Practice Guidelines. J Am Coll Cardiol. 2012:60:645-81.

2. Tanguay JF, Bell AD, Ackman ML, Bauer RD, Cartier R, Chan WS, et al Focused 2012 update of the Canadian Cardiovascular Society guidelines for the use of antiplatelet therapy. Can J Cardiol. 2013;29:1334-45.

3. Yusuf S, Zhao F, Mehta SR, Chrolavicius S, Tognoni G, Fox KK, et al. Effects of clopidogrel in addition to aspirin in patients with acute coronary syndromes without ST-segment elevation. N Engl J Med. 2001;345:494-502.

4. Wiviott SD, Braunwald E, McCabe CH, Montalescot G, Ruzyllo W, Gottlieb S, et al. Prasugrel versus clopidogrel in patients with acute coronary syndromes. N Engl J Med. 2007;357:2001-15.

5. Wallentin L, Becker RC, Budaj A, Cannon CP, Emanuelsson H, Held C, et al. Ticagrelor versus clopidogrel in patients with acute coronary syndromes. $\mathrm{N}$ Engl J Med. 2009;361:1045-57.

6. Fitchett D, Eikelboom J, Fremes S, Mazer D, Singh S, Bittira B, et al. Dual antiplatelet therapy in patients requiring urgent coronary artery bypass grafting surgery: a position statement of the Canadian Cardiovascular Society. Can J Cardiol. 2009;25:683-9.

7. Fitchett D, Mazer CD, Eikelboom J, Verma S. Antiplatelet therapy and cardiac surgery: review of recent evidence and clinical implications. Can J Cardiol. 2013:29:1042-7.

8. Krimly A, Yan RT, Yan AT, DeYoung JP, Gallo R, Steg G, et al. Use of clopidogrel post-coronary artery bypass surgery in canadian patients with acute coronary syndromes. Can J Cardiol. 2011;27:711-5.

9. Rao RV, Goodman SG, Yan RT, Spencer FA, Fox KA, DeYoung JP, et al. Temporal trends and patterns of early clopidogrel use across the spectrum of acute coronary syndromes. Am Heart J. 2009;157:642-50. e641.

10. Groeneveld PW, Hlatky MA. Commentary. Evid Based Med. 2001;6:114.

11. Smith PK, Goodnough LT, Levy JH, Poston RS, Short MA, Weerakkody GJ, et al. Mortality benefit with prasugrel in the TRITON-TIMI 38 coronary artery bypass grafting cohort: risk-adjusted retrospective data analysis. J Am Coll Cardiol. 2012;60:388-96.

12. DerSimonian R, Laird N. Meta-analysis in clinical trials. Control Clin Trials. 1986;7:177-88.

13. Higgins JP, Thompson SG, Deeks JJ, Altman DG. Measuring inconsistency in meta-analyses. BMJ. 2003;327:557-60.

14. Sterne JAC, Egger M, Moher D. Cochrane Handbook for Systematic Reviews of Interventions. Version 5.1.0. Chapter 10: Addressing reporting biases. In. Edited by Higgins JPT, Green S: The Cochrane Collaboration; 2011.

15. Gao G, Zheng Z, Pi Y, Lu B, Lu J, Hu S. Aspirin plus clopidogrel therapy increases early venous graft patency after coronary artery bypass surgery a single-center, randomized, controlled trial. J Am Coll Cardiol. 2010;56:1639-43.

16. Sun JC, Teoh KH, Lamy A, Sheth T, Ellins ML, Jung H, et al. Randomized trial of aspirin and clopidogrel versus aspirin alone for the prevention of coronary artery bypass graft occlusion: the Preoperative Aspirin and Postoperative Antiplatelets in Coronary Artery Bypass Grafting study. Am Heart J. 2010;160:1178-84.

17. Held C, Asenblad N, Bassand JP, Becker RC, Cannon CP, Claeys MJ, et al. Ticagrelor versus clopidogrel in patients with acute coronary syndromes undergoing coronary artery bypass surgery: results from the PLATO (Platelet Inhibition and Patient Outcomes) trial. J Am Coll Cardiol. 2011;57:672-84.

18. Saw J, Topol EJ, Steinhubl SR, Brennan D, Berger PB, Moliterno DJ, et al. Comparison of long-term usefulness of clopidogrel therapy after the first percutaneous coronary intervention or coronary artery bypass grafting versus that after the second or repeat intervention. Am J Cardiol. 2004;94:623-5.

19. Fox KA, Mehta SR, Peters R, Zhao F, Lakkis N, Gersh BJ, et al. Benefits and risks of the combination of clopidogrel and aspirin in patients undergoing surgical revascularization for non-ST-elevation acute coronary syndrome: the Clopidogrel in Unstable angina to prevent Recurrent ischemic Events (CURE) Trial. Circulation. 2004;110:1202-8.

20. Steinhubl SR, Berger PB, Mann III JT, Fry ET, DeLago A, Wilmer C, et al. Early and sustained dual oral antiplatelet therapy following percutaneous coronary intervention: a randomized controlled trial. JAMA. 2002;288:2411-20.
21. Kulik A, Le May MR, Voisine P, Tardif JC, Delarochelliere R, Naidoo S, et al. Aspirin plus clopidogrel versus aspirin alone after coronary artery bypass grafting: the clopidogrel after surgery for coronary artery disease (CASCADE) Trial. Circulation. 2010;122:2680-7.

22. Mannacio VA, Di Tommaso L, Antignan A, De Amicis V, Vosa C. Aspirin plus clopidogrel for optimal platelet inhibition following off-pump coronary artery bypass surgery: results from the CRYSSA (prevention of Coronary arteRY bypaSS occlusion After off-pump procedures) randomised study. Heart. 2012;98:1710-5.

23. Gasparovic H, Petricevic M, Kopjar T, Djuric Z, Svetina L, Biocina B. Impact of dual antiplatelet therapy on outcomes among aspirin-resistant patients following coronary artery bypass grafting. Am J Cardiol. 2014;113:1660-7.

24. Gao C, Ren C, Li D, Li L. Clopidogrel and aspirin versus clopidogrel alone on graft patency after coronary artery bypass grafting. Ann Thorac Surg. 2009;88:59-62.

25. Kayacioglu I, Gunay R, Saskin H, Idiz M, Sensoz Y, Ates M, et al. The role of clopidogrel and acetylsalicylic acid in the prevention of early-phase graft occlusion due to reactive thrombocytosis after coronary artery bypass operation. Heart Surg Forum. 2008;11:E152-157.

26. Mujanovic E, Nurkic M, Caluk J, Terzic I, Kabil E, Bergsland J. The effect of combined clopidogrel and aspirin therapy after off-pump coronary surgery: a pilot study. Innovations (Phila). 2009;4:265-8.

27. Nielsen AB, Bochsen L, Steinbruchel DA. Hypercoagulability and platelet inhibition after OPCAB. Randomized intervention with clopidogrel. Scand Cardiovasc J. 2007:41:325-30.

28. Wang X-Z, Gong X-X, Zhu T-T, Li C-J, Yang Z-J. Effect of aspirin plus clopidogrel therapy on aspirin resistance after off-pump coronary artery bypass surgery [Chinese]. Acta Acad Med Sinicae. 2013;35:495-502.

29. Saw JW, Wong G, Mayo J, Bernstein V, Mancini GB, Ye J, et al. Ticagrelor and Aspirin for the Prevention of Cardiovascular Events After Coronary Artery Bypass Surgery: The TAP-CABG Study. J Am Coll Cardiol. 2015;65:A1638.

30. Thopte OS, Patil SP, Deshmukh RS. A study of aspirin plus clopidogrel versus aspirin alone on saphenous vein graft patency after coronary artery bypass graft surgery-an angiographic follow-up after three months. Indian Heart Journal. 2014;66:S22.

31. Wang X, Gong X, Zhu T, Zhang Q, Zhang Y, Wang X, et al. Clopidogrel improves aspirin response after off-pump coronary artery bypass surgery. J Biomed Res. 2014;28:108-13.

32. David JL, Limet R. Antiplatelet activity of clopidogrel in coronary artery bypass graft surgery patients. Thromb Haemost. 1999;82:1417-21.

33. Lim E, Cornelissen J, Routledge T, Kirtland S, Charman SC, Bellm S, et al. Clopidogrel did not inhibit platelet function early after coronary bypass surgery: A prospective randomized trial. J Thorac Cardiovasc Surg. 2004;128:432-5.

34. Suwalski G, Smoczycski R, Banach M, Gryszko L, Szaaacski P, Krawczyk K, Hendzel P. Aspirin versus clopidogrel after off-pump coronary artery bypass grafting: Prospective, randomized head-to-head trial. In: 15th Annual Meeting of the International Society for Minimally Invasive Cardiothoracic Surgery. vol. 7. Los Angeles; 2012: 138

35. Tetik S, Ak K, Isbir S, Eksioglu-Demiralp E, Arsan S, Iqbal O, et al. Clopidogrel provides significantly greater inhibition of platelet activity than aspirin when combined with atorvastatin after coronary artery bypass grafting: a prospective randomized study. Clin Appl Thromb Hemost. 2010;16:189-98.

36. Cornelissen J, Kirtland S, Lim E, Goddard M, Bellm S, Sheridan K, et al. Biological efficacy of low against medium dose aspirin regimen after coronary surgery: analysis of platelet function. Thromb Haemost. 2006;95:476-82.

37. Lim E, Cornelissen J, Routledge T, Ali A, Kirtland S, Sharples L, et al. Biological efficacy of low versus medium dose aspirin after coronary surgery: results from a randomized trial [NCT00262275]. BMC Med. 2006;4:12.

38. Bhatt DL, Fox KA, Hacke W, Berger PB, Black HR, Boden WE, et al. Clopidogrel and aspirin versus aspirin alone for the prevention of atherothrombotic events. N Engl J Med. 2006;354:1706-17.

39. Cannon CP, Husted S, Harrington RA, Scirica BM, Emanuelsson H, Peters G, et al. Safety, tolerability, and initial efficacy of AZD6140, the first reversible oral adenosine diphosphate receptor antagonist, compared with clopidogrel, in patients with non-ST-segment elevation acute coronary syndrome: primary results of the DISPERSE-2 trial. J Am Coll Cardiol. 2007;50:1844-51.

40. Chen ZM, Jiang LX, Chen YP, Xie JX, Pan HC, Peto R, et al. Addition of clopidogrel to aspirin in 45,852 patients with acute myocardial infarction: randomised placebo-controlled trial. Lancet. 2005;366:1607-21.

41. Roe MT, Armstrong PW, Fox KA, White HD, Prabhakaran D, Goodman SG, et al. Prasugrel versus clopidogrel for acute coronary syndromes without revascularization. N Engl J Med. 2012;367:1297-309. 
42. Wiviott SD, Antman EM, Winters KJ, Weerakkody G, Murphy SA, Behounek BD, et al. Randomized comparison of prasugrel (CS-747, LY640315), a novel thienopyridine P2Y12 antagonist, with clopidogrel in percutaneous coronary intervention: results of the Joint Utilization of Medications to Block Platelets Optimally (JUMBO)-TIMI 26 trial. Circulation. 2005;111:3366-73.

43. McLean DS, Sabatine MS, Guo W, McCabe CH, Cannon CP. Benefits and risks of clopidogrel pretreatment before coronary artery bypass grafting in patients with ST-elevation myocardial infarction treated with fibrinolytics in CLARITY-TIMI 28. J Thromb Thrombolysis. 2007;24:85-91.

44. Mehta SR, Bassand JP, Chrolavicius S, Diaz R, Eikelboom JW, Fox KA, et al. Dose comparisons of clopidogrel and aspirin in acute coronary syndromes. N Engl J Med. 2010;363:930-42.

45. Bhatt DL, Chew DP, Hirsch AT, Ringleb PA, Hacke W, Topol EJ. Superiority of clopidogrel versus aspirin in patients with prior cardiac surgery. Circulation. 2001;103:363-8.

46. Brilakis ES, Held C, Meier B, Cools F, Claeys MJ, Cornel JH, et al. Effect of ticagrelor on the outcomes of patients with prior coronary artery bypass graft surgery: insights from the PLATelet inhibition and patient outcomes (PLATO) trial. Am Heart J. 2013;166:474-80.

47. Whellan DJ, Tricoci P, Chen E, Huang Z, Leibowitz D, Vranckx P, et al. Vorapaxar in acute coronary syndrome patients undergoing coronary artery bypass graft surgery: subgroup analysis from the TRACER trial (Thrombin Receptor Antagonist for Clinical Event Reduction in Acute Coronary Syndrome). J Am Coll Cardiol. 2014;63:1048-57.

48. Rafiq S, Johansson PI, Zacho M, Stissing T, Kofoed K, Lilleor NB, et al. Thrombelastographic haemostatic status and antiplatelet therapy after coronary artery bypass surgery (TEG-CABG trial): assessing and monitoring the antithrombotic effect of clopidogrel and aspirin versus aspirin alone in hypercoagulable patients: study protocol for a randomized controlled trial. Trials. 2012;13:48.

49. Eli Lilly and Company, Sankyo D. Effient (Prasugrel) Acute Coronary Syndromes Managed by Percutaneous Coronary Intervention. 2009. http://www.fda.gov/downloads/AdvisoryCommittees/CommitteesMeeting Materials/Drugs/CardiovascularandRenalDrugsAdvisoryCommittee/ ucm129219.pdf

50. Goodnough LT, Smith PK, Levy JH, Poston RS, Short MA, Weerakkody GJ, et al. Transfusion outcomes in patients undergoing coronary artery bypass grafting treated with prasugrel or clopidogrel: TRITON-TIMI 38 retrospective data analysis. J Thorac Cardiovasc Surg. 2013;145:1077-82. e1074.

51. Mehran R, Rao SV, Bhatt DL, Gibson CM, Caixeta A, Eikelboom J, et al. Standardized bleeding definitions for cardiovascular clinical trials: a consensus report from the Bleeding Academic Research Consortium. Circulation. 2011;123:2736-47.

52. Gurbel PA, Bliden KP, Butler K, Tantry US, Gesheff T, Wei C, et al. Randomized double-blind assessment of the ONSET and OFFSET of the antiplatelet effects of ticagrelor versus clopidogrel in patients with stable coronary artery disease: the ONSET/OFFSET study. Circulation. 2009;120:2577-85.

53. Bonello L, Laine M, Kipson N, Mancini J, Helal O, Fromonot J, et al. Ticagrelor increases adenosine plasma concentration in patients with an acute coronary syndrome. J Am Coll Cardiol. 2014;63:872-7.

54. DiNicolantonio JJ, D'Ascenzo F, Tomek A, Chatterjee S, Niazi AK, BiondiZoccai G. Clopidogrel is safer than ticagrelor in regard to bleeds: a closer look at the PLATO trial. Int J Cardiol. 2013;168:1739-44.

55. Husted S, James S, Becker RC, Horrow J, Katus H, Storey RF, et al. Ticagrelor versus clopidogrel in elderly patients with acute coronary syndromes: a substudy from the prospective randomized PLATelet inhibition and patient Outcomes (PLATO) trial. Circ Cardiovasc Qual Outcomes. 2012;5:680-8.

56. Deo SV, Dunlay SM, Shah IK, Altarabsheh SE, Erwin PJ, Boilson BA, et al. Dual anti-platelet therapy after coronary artery bypass grafting: is there any benefit? A systematic review and meta-analysis. J Card Surg. 2013;28:109-16.

57. Nocerino AG, Achenbach S, Taylor AJ. Meta-analysis of effect of single versus dual antiplatelet therapy on early patency of bypass conduits after coronary artery bypass grafting. Am J Cardiol. 2013;112:1576-9.

58. Li JH, Aikeremu MT, Zhang MM, Yilihamu A. Effectiveness and Safety of Dual Anti-platelet Therapy after Coronary Artery Bypass Grafting: A Meta-Analysis [Chinese]. Chin J Evid-based Med. 2014;14:958-65.

59. de Leon N, Jackevicius CA. Use of aspirin and clopidogrel after coronary artery bypass graft surgery. Ann Pharmacother. 2012;46:678-87.

60. Nagarajan DV, Lewis PS, Dunning J. Is clopidogrel beneficial following coronary bypass surgery? Interact Cardiovasc Thorac Surg. 2004;3:311-3.
61. Patel JH, Stoner JA, Owora A, Mathew ST, Thadani U. Evidence for using clopidogrel alone or in addition to aspirin in post coronary artery bypass surgery patients. Am J Cardiol. 2009;103:1687-93.

62. Biondi-Zoccai G, Lotrionte M, Agostoni P, Abbate A, Romagnoli E, Sangiorgi $\mathrm{G}$, et al. Adjusted indirect comparison meta-analysis of prasugrel versus ticagrelor for patients with acute coronary syndromes. Int J Cardiol. 2011;150:325-31.

63. Chatterjee S, Ghose A, Sharma A, Guha G, Mukherjee D, Frankel R Comparing newer oral anti-platelets prasugrel and ticagrelor in reduction of ischemic events-evidence from a network meta-analysis. J Thromb Thrombolysis. 2013;36:223-32.

64. Cao C, Indraratna P, Ang SC, Manganas C, Park J, Bannon PG, et al. Should clopidogrel be discontinued before coronary artery bypass grafting for patients with acute coronary syndrome? A systematic review and metaanalysis. J Thorac Cardiovasc Surg. 2014;148(6):3092-8.

65. Au AG, Majumdar SR, McAlister FA. Preoperative thienopyridine use and outcomes after surgery: a systematic review. Am J Med. 2012;125:87-99. e81.

66. Biancari F, Airaksinen KE, Lip GY. Benefits and risks of using clopidogrel before coronary artery bypass surgery: systematic review and meta-analysis of randomized trials and observational studies. J Thorac Cardiovasc Surg. 2012;143:665-75. e664

67. Guay J, Andrew Ochroch E. Continuing antiplatelet therapy before cardiac surgery with cardiopulmonary bypass: a meta-analysis on the need for reexploration and major outcomes. J Cardiothorac Vasc Anesth. 2014;28:90-7.

68. Ma J, Xu W-J, Xu G-P. Impact of perioperative use of clopidogrel on coronary bypass grafting patients: a meta-analysis. Chin J Evid-Based Med. 2013;13:827-35.

69. Nijjer SS, Watson G, Athanasiou T, Malik IS. Safety of clopidogrel being continued until the time of coronary artery bypass grafting in patients with acute coronary syndrome: a meta-analysis of 34 studies. Eur Heart J. 2011;32:2970-88.

70. Purkayastha S, Athanasiou T, Malinovski V, Tekkis P, Foale R, Casula R, et al. Does clopidogrel affect outcome after coronary artery bypass grafting? A meta-analysis. Heart. 2006;92:531-2.

71. Steiner S, Moertl D, Chen L, Coyle D, Wells GA. Network meta-analysis of prasugrel, ticagrelor, high- and standard-dose clopidogrel in patients scheduled for percutaneous coronary interventions. Thromb Haemost. 2012;108:318-27.

72. Biancari F, Juvonen T. Does clopidogrel improve the long-term outcome after coronary artery bypass surgery? Scand Cardiovasc J. 2005;39:135-6.

73. De Servi S, Savonitto S. How to explain the reduced cardiovascular mortality in the ticagrelor arm of the PLATO trial? Int J Cardiol. 2011;149:265-7.

74. Montalescot G, Hulot JS, Collet JP. Antiplatelet therapy and coronary artery bypass graft surgery a fallow land. J Am Coll Cardiol. 2010;56:2003-5.

75. Shrivastava $\mathrm{V}$, Akowuah E. Impact of clopidogrel in coronary artery bypass grafting. Eur J Cardiothorac Surg. 2005;27:176-7.

76. Verheugt FW. Clopidogrel versus aspirin after cardiac surgery. Circulation. 2001;104:E76.

77. Gurbuz AT, Zia AA, Vuran AC, Cui H, Aytac A. Postoperative clopidogrel improves mid-term outcome after off-pump coronary artery bypass graft surgery: a prospective study. Eur J Cardio-thorac Surg. 2006;29:190-5.

78. Ibrahim K, Tjomsland O, Halvorsen D, Wiseth R, Wahba A, Karevold A, et al. Effect of clopidogrel on midterm graft patency following off-pump coronary revascularization surgery. Heart Surg Forum. 2006;9:E581-856.

\section{Submit your next manuscript to BioMed Central and take full advantage of:}

- Convenient online submission

- Thorough peer review

- No space constraints or color figure charges

- Immediate publication on acceptance

- Inclusion in PubMed, CAS, Scopus and Google Scholar

- Research which is freely available for redistribution 